\section{EFFECT OF HIGH ASPECT RATIO ON ITER} MAINTENANCE DESIGN*

CONF-910968--34

DE92 002319

T. J. Herrick, F. C. Davis, M. J. Hollis, and D. C. Lousteau

Martin Marietta Energy Systems, Inc.

Oak Ridge National Laboratory

Oak Ridge, TN. 37831-635j

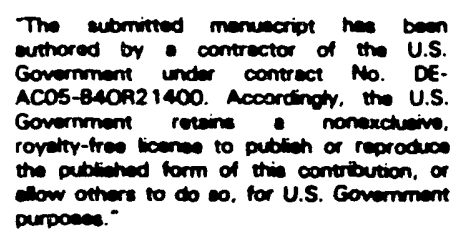

To be presented at the 14th

Symposium on Fusion Engineering

San Diego, California

September 30-October 3, 1991

\title{
DISCLAIMER
}

This report was prepared as an account of work sponsored by an agency of the United States Government. Neither the United States Government nor any agency thereof, nor any of their employees, makes any warranty, express or implied, or assumes any legal liability or responsibility for the accuracy, completeness, or usefulness of any information, apparatus, product, or process disclosed, or represents that its use would not infringe privately owned rights. Reference herein to any specific commercial product, process, or service by trade name, trademark, manufacturer, or otherwise does not necessarily constitute or imply its endorsement, recommendation, or favouing by the United States Government or any agency thereof. The views and opinions of authors expressed herein do not necessarily state or reflect those of the United States Government or any agency thereof. 


\title{
EFFECT OF HIGH ASPECT RATIO .ON ITER MAINTENANCE DESIGN
}

\author{
T. J. Herrick, F. C. Davis, M. J. Hollis, D. C. Lousteau, \\ Martin Marietta Energy Systems, Inc. \\ Oak Ridge National Laboratory, Oak Ridge, TN 37831-6353
}

\begin{abstract}
$\underline{\text { Abstract }}$
The International Thermonuclear Experimental Reactor (ITER) baseline machine configuration and auxiliary systems design specify maintainability and repairability as fundamental requirements. Two important maintenance requirements for ITER are a device that is fully remotely maintainable, with the provision for hands-on maintenance wherever possible, and the ability to maintain components with short lives or high failure rates without moving other components or disturbing the machine's internal or external environment. Some of the maintenance tasks are accomplished through the use of specialized remote maintenance equipment that will perform crucial in-vessel and ex-vessel operations. In-vessel maintenance will be performed with a combination of horizontal and vertical access. Since the completion of the Conceptual Design Activity (CDA), systems studies by the U.S. ITER design team have pointed to the possible benefits of a high aspect ratio design (HARD). The alternative HARD has been shown to have better performance characteristics than the present baseline. The HARD machine configuration modified in size a number of major components that must be remotely maintained or replaced. This required reevaluation of the maintenance scenarios of these components with respect to changes in physical accessibility, assembly and disassembly, and remote maintenance equipment. The CDA baseline design and HARD are compared from an assembly and maintenance feasibility perspective for some critical operations.
\end{abstract}

\section{Introduction}

The components of the ITER machine ${ }^{1}$ are classified according to their requirements for maintenance, which are derived from each component's predicted need for scheduled or unscheduled maintenance, the likelihood of maintenance, and the impact of the maintenance concept on operations and availability.

\footnotetext{
* Research sponsored by the Office of Fusion Energy, U.S. Department of Energy, under contract DE-AC0584OR21400 with Martin Marietta Energy Systems, Inc.
}

Class 1 components are those that will require frequent scheduled maintenance (e.g., the divertor plates). These components will be remotely maintained; the minimization of replacement time is a major requirement. Class 2 components are those that are designed to last the life of ITER but may require unscheduled remote maintenance or replacement (e.g., the in-vessel breeding blanket modules). Nuclear performance and operational reliability are critical for these semi-permanent components ${ }^{1}$. Class 3 components are those classified as "permanent" such as the vacuum vessei and the toroidal field (TF) and poloidal field (PF) magnets. These components are expected to last the life of ITER without major maintenance If maintenance or replacement of these components is required, major disassembly of a portion of the tokamak will be necessary and the projected maintenance time will be long 1 .

The effects of the alternative HARD on the baseline assembly/maintenance concepts and equipment are studied for some major components and critical maintenance operations of these components.

\section{Size and Weight}

The HARD modified in size a number of components that will require remote assembly and maintenance. Figure 1, a section view between the TF coils for both configurations, provides a general size comparison.

The main crane located above the reactor assembly will be used for initial assembly and later for remote maintenance. Table 1 lists the weights of the largest components to be handled by the main crane and of the major in-vessel Class 1 and 2 components for both designs.

The weight of the central solenoid substantially increased in the HARD. The weights listed do not include the weights of handling fixtures for each component. Therefore, a main crane capacity in excess of 1000 tons will be required. The slight increases in in-vessel component weights will not adversely affect ex-vessel component lifting and handling equipment. 
Table 1.0: Weight (in tons) of major components

\section{Weight"}

\section{Component}

Central Solenoid

Cryostat Top

Divertor

Inboard Blanket/Shield

Module

Lower Inboard Plug

Side Outboard Blanket/

Shield Module and Upper

Plug

Upper Central Outboard

Blanket/Shield Module

Lower Central Outboard

Blanket/Shield Module

\section{CDA Design $^{1}$}

720

700

1.5

40

20

80

64

35

37
HARD

986

800

1.7

36

20.5

76

67
'Derived by scaling component volumes.

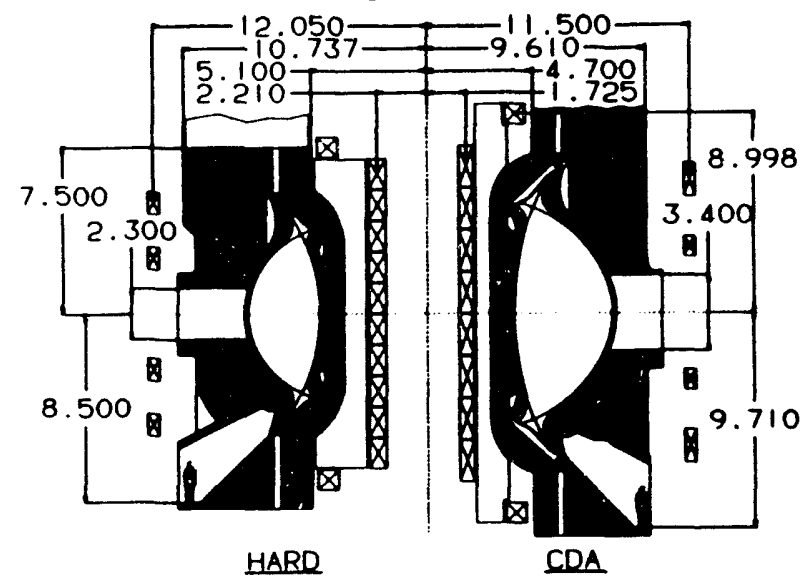

Figure 1 - HARD-C.DA Comparison

\section{Top Vertical Port Design and Maintenance Operations}

The design and maintenance concepts for the 16 top vertical ports were recently established for the CDA baseline design. The blanket/shield modules will be replaced through the top vertical ports. Each of these ports contains 48 pipes ranging from $20 \mathrm{~mm}$ OD to $168.3 \mathrm{~mm}$ OD that provide cooling services for the blanket modules. A portion of each pipe must be removed in order for the blanket modules to be replaced. The top port is designed so that this operation can be done remotely without violating the vacuum integrity of the vacuum vessel. Other primary maintenance tasks required before the blanket modules can be maintained include the breaking/remaking of the vacuum port seal welds at various locations, cutting/welding of divertor piping, and replacement of pipe bellows in the top port region. High radiation levels require that all of these tasks be performed remotely with manipulators and specialized maintenance equipment.

\subsection{Piping Layout and Removal/Replacement Concepts}

The HARD did not affect the proposed piping design and maintenance concept for the baseline design. A pipe jumper design (see Fig. 2.) is proposed for both the HARD and the baseline design. All piping extends vertically from the top of each blanket segment through a transition plate with the inner joint of each jumper above the transition plate. The pipe jumper (see Fig. 3) consists of two Cefilac Type " $\mathrm{V}$ " mechanical flanges that are permanently attached to the jumper piping. A Helicoflex seal is secured to the pipe flange on the jumper. The opening and closing of the clamp is determined by which direction the bolt is turned and can be accomplished from either end of the bolt. This ease of operation enables the jumper to be assembled/disassembled remotely with a manipulator that is inserted into the top of the port. A stairstep layout of the pipe jumpers enables the jumpers to be removed without interference from adjacent piping/pipe jumpers.

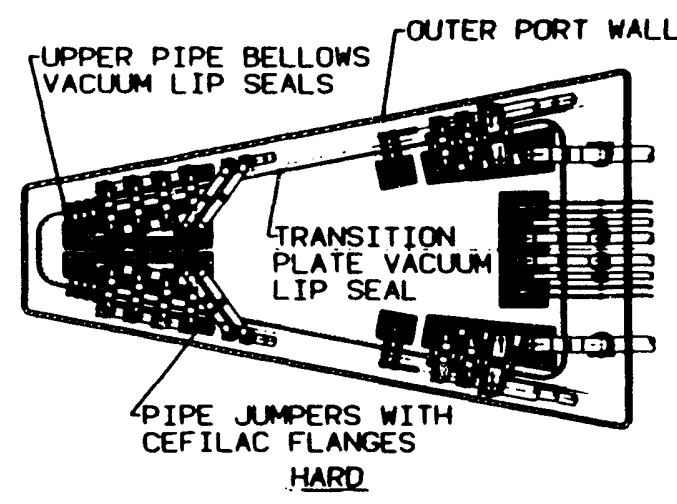

Figure 2 - Top Port Pipe Jumper Layout

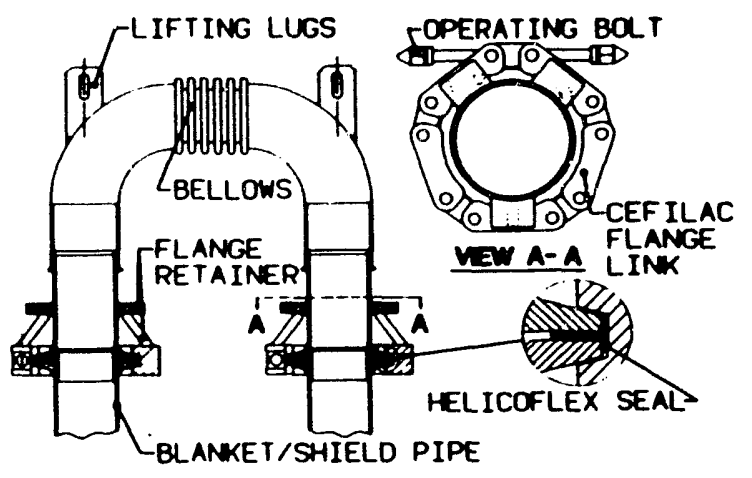

Figure 3 - Top Port Pipe Jumper w/Cefilac "V" Flange

Conventional cutting and welding is an alternative for removing the required piping sections. However, the tight horizontal spatial configuration of the port and the blanket modules severely limits the alternatives for arranging the vertical blanket piping. The lack of proper clearance between pipes might eliminate the conventional cutter/welder as an alternative. The cutter/welder would have to be remotely operable/maintainable and would have 
to perform a minimum of 96 cuts and rewelds. Similar commercial technology does exist, but a development effort would be expected.

The shape of the port is driven by the configuration of the TF coils. Both the HARD and the CDA design have 16 vertical ports. The overall length of the CDA port is 4910 $\mathrm{mm}$; that of the HARD port is $5637 \mathrm{~mm}$ (see Figs. 4 and 5). The HARD port length had to be increased by $727 \mathrm{~mm}$ so that the inboard blanket segments could be withdrawn during blanket/shield module removal without interference from the side outboard blanket segments. The inboard blanket segments protrude through the upper vertical port at the tapered end of the port. These protrusions are adjacent to each other in the top port. The CDA design showed an offset in one of the inboard blanket protrusions in order to centralize the piping that passes through the blanket to the divertors into one inboard blanket segment. However, it has been verified (see Sect. 3.2) that the inboard blanket/shield module with the offset cannot be removed with the side outboard blanket segments in the vessel. The same interference was encountered with the HARD. Therefore, it has been decided to eliminate the offset and have a straight-line cut. This design change makes it possible to remove the inboard blanket shields without removing the side outboard blanket segments for both the HARD and the CDA design. The length of the inboard blanket/shield module protrusion increased from $1110 \mathrm{~mm}$ (CDA) to $1715 \mathrm{~mm}$ (HARD). This increase enabled the top port blanket piping for the inboard blanket/shield modules to be moved farther apart. This will aid in performing the remote maintenance in this area, which is already congested with blanket/shield module piping. The layout of the piping for the other blanket/shield segments did not significantly change for the HARD.

\subsection{Cutting/Rewelding of Divertor Piping}

The divertor plate is a Class 1 component that will be remotely maintained with specialized in-vessel maintenance equipment. Before the divertors can be removed, the divertor piping will have to be internally cut as close to the divertor as possible. The divertor piping on the replacement divertor will also have to be welded internally. The HARD did not change or eliminate any of maintenance or operational requirements previously established by the CDA design.

The divertor piping is located on each of the inboard blanket /shield modules in the upper port (see Figs. 4 and 5) and is accessible at a location above the cryostat cover. The internal pipe cutting/welding tool is introduced into the divertor piping from this ex-vessel location and lowered to the appropriate location in the piping.

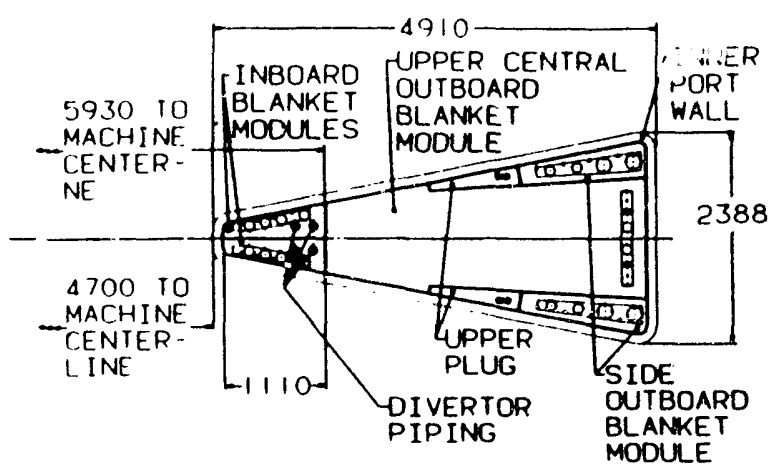

Figure 4 - Top Port CDA Piping Layout

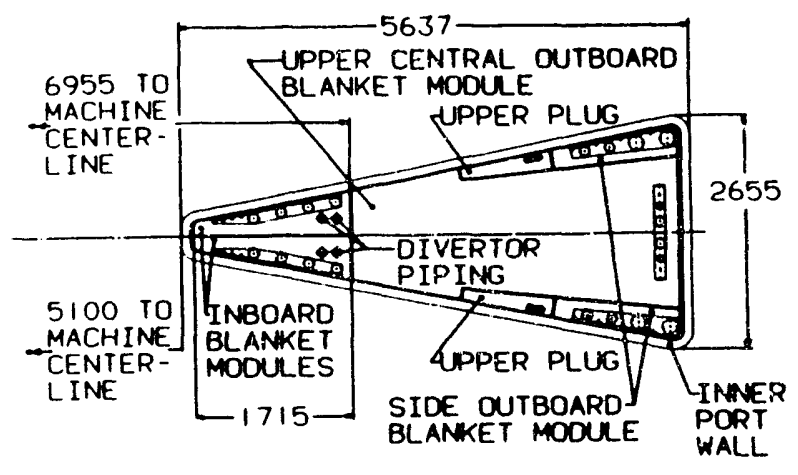

Figure 5 - Top Port HARD Piping Layout

Different concept alternatives for the internal cutting/welding of divertor piping can be considered. Equipment that periorms conventional cutting and arc welding does exist. A development effort would be required to miniaturize the components and also verify reliability in harsh environments. Laser beam cutting/welding is the recommended choice for this remote operation. Delivery of the laser beam to the working area will be a challenge because of the size of ITER. The use of conventional multimirror beam delivery systems will require expensive custom design and development, with beam alignment and stability being major concerns. An alternative is a flexible fiber-optic laser beam delivery system. These systems exist commercially for remote processing and for use in radioactive environments. The iaser beam can be delivered to a small compact output housing. After exiting the housing, the laser beam is then reflected $90^{\circ}$ from a rotating mirror and the divertor piping is cut or welded.

\subsection{Breaking/Remaking of Vacuum Seal Welds}

After the divertor piping has been cut and the pipe jumpers have been removed, a number of viacuum seal welds will have to be broken to allow blanket/shield module removal. The transition plate seal welds will consist of a circumferential lip-seal weld and several lip-seal welds attaching pipe bundle bellows (see Fig. 6). A pipe bundle bellows will be located around each blanket/shield module 
pipe bundle and will attach to the transition plate and the top of each blanket/shield module in order to isolate the secondary vacuum chamber and the vacuum vessel. These operations will have to be done remotely before the transition plate can be removed. All vacuum seal welds will have to be remade remotely when the transition plate is reinstalled. Should a pipe bellows need to be replaced independently, the bottom pipe bellows flange will need to be accessible for remote cutting/welding.

The HARD does not affect the proposed CDA design and maintenance concepts for breaking/remaking of the vacuum seal welds. A number of concepts have been considered for these remote operations, but because of tight spatial restrictions for both the HARD and CDA designs, these alternatives did not seem feasible.

The proposed concept for these applications is laser beam curting and welding (see Fig. 6). A fiber-optic laser beam delivery system, as previously discussed for the divertor pipe cutting/welding can be considered. Fiber-optic laser beam output housings (see Fig. 6) are commercially available in sizes ranging from $25.4 \mathrm{~mm}$ to $76.2 \mathrm{~mm} O D$, depending on the required laser power. Multiple output housings can be used in series if space restrictions limit the required laser power and the size of the laser output housing needed to process the material. Maximum average laser power available is $1 \mathrm{kw}$ with the ability to cut steel up to $8 \mathrm{~mm}$ thick and weld steel with a $5 \mathrm{~mm}$ penetration. This concept is also proposed for cutting and rewelding the lower pipe bellows flange located at the top of the blanket/shield modules. A manipulator with special access tools will be used to guide the fiber-optic laser beam delivery system along the lip seals and bellows flanges. The manipulator system should be computer controlled with a viewing/tracking system to monitor material processing. A development effort will be required to customize the laser welding/cutting concept for the propused ITER applications. Accessibility to the lower bellows flange was improved with the HARD.

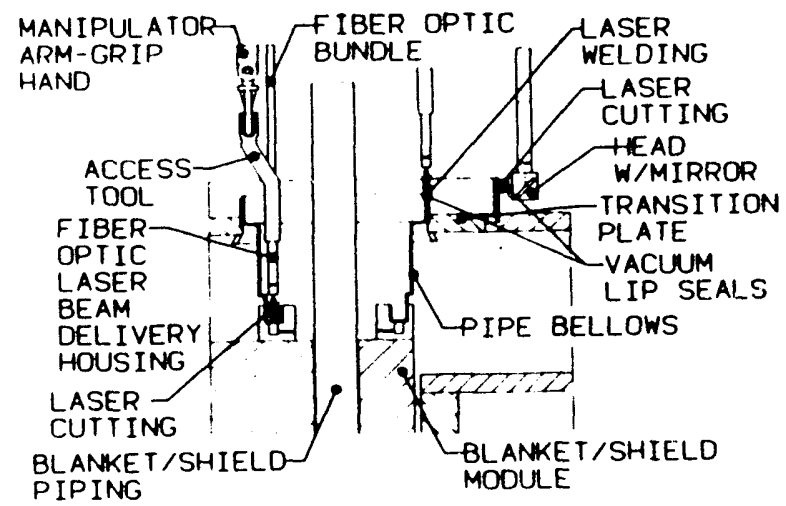

Figure 6 - Top Port Vacuum Seals
3. Segmentation and In-Vessel Removal Schemes for Divertors and Blanket/Shield Modules

Included in the scope of maintenance tasks for both the CDA design and the HARD is the requirement for removal of all divertors and blanket/shield modules. This requirement prompted an investigation of the removal of these components through upper vertical and midplane horizontal vacuum vessel ports. A study was conducted using a three-dimensional (3-D) computer software modeling package named the Interactive Graphic Robotic Instruction Program (IGRIP). The software has both collision detection and kinematic property assignment capabilities, making it an excellent tool for the study.

\subsection{Divertors}

In the CDA baseline design, the divertors will be remotely maintained through the use of an in-vessel transporter, an in-vesse! vehicle/rail or articulated boom, which will be deployed toroidally to the required position in the vessel. Both concepts are to be equipped with remote manipulators, divertor handling fixtures and special tools. The transporters will be deployed into the vessel through two midplane horizontal ports located $180^{\circ}$ apart. A total of 64 divertor plates (32 upper and 32 lower) exist for both the baseline design and HARD. The baseline divertor is $3.4 \mathrm{~m}$ long, 1.2 to $0.8 \mathrm{~m}$ wide, and $0.2 \mathrm{~m}$ thick, while the HARD divertor is $3.2 \mathrm{~m}$ long, 1.37 to $0.9 \mathrm{~m}$ wide, and $0.2 \mathrm{~m}$ thick. These dimensions reveal a minor change in divertor weight, as shown in Sect. 1.

The removal of the CDA design divertors required 8 motions while the HARD divertor removal required 9 motions. The first eight motions and physical restraints for each motion were identical in each design. The HARD design required an additional inverting rotary motion in order to clear a smaller horizontal port.

The minimum clearances in the divertor removal procedure occurred within the first three steps of motion. The most difficult problem was posed by the clearances, 50 $\mathrm{mm}$ (HARD) and $75 \mathrm{~mm}$ (CDA), between the divertor and the lower inboard plugs during the initial translation and local rotation. This clearance, coupled with the inverting rotation and close midplane port clearances, makes the HARD the less desirable of the two cases for simple motion divertor removal.

Although mechanical equipment was not investigated for this study, some consideration was given to both the CDA design and the HARD divertor removal schemes and to the removal equipment concepts presented for the CDA design. The HARD design does not lend itself to the use of the vehicle/rail system due to the necessity for the inverting rotational motion of the divertor. Although the transport rail could feasibly be raised and/or lowered for this task, it 
inay not be possible to allow enough space between the rail and the divertor to place the divertor in the out-of-vessel carrier. The CDA design lends itself to both the vehicle/rail and articulated boom designs.

\subsection{Blanket/Shield Modules}

The blanket/shield modules are classified as Class 2 components, so replacement of these components should be expected during the life of ITER ${ }^{1}$. Remote assembly/replacement of the blanket assembly modules in the vacuum vessel through the large top vertical port will require precise vertical and horizontal positioning of large heavy blanket/shield modules with irregular shapes. The unusual shapes and centers of gravity of the blankets require special ex-vessel handling equipment for blanket removal in conjunction with the overhead crane. Tight clearances between the blanket modules contribute to the complexity of the task.

The blanket assembly sequence is greatly affected by the blanket/shield module segmentation. The segmentation scheme developed during the CDA was used as the baseline for these conducted studies. The blanket segments are divided into inboard and outboard regions. Each of the 16 toroidally assembled blanket segments is removed through 1 of the 16 top vertical ports. Each blanket segment consists of two inboard blanket modules, two lower inboard plugs, two upper outboard plugs, two side outboard blanket modules, an upper central outboard blanket module, and a lower central outboard blanket module. The HARD uses the same blanket modules but with modified blanket contours and cuts, as shown in Fig. 1. The inboard modules are considered to have the highest probability of failure. They are also the most difficult sections of the blanket segment to remove.

Several assumptions were made in comparing removal sequences of the CDA design and the HARD. First, it was assumed that the outboard module sections of the blanket segment were less likely to fail or require maintenance than the inboard modules. Also, removal of these modules may increase their probability of failure and should only be performed when the maintenance task is outboard specific. Therefore, it was established that the inboard blanket modules should be removable with the outboard modules in place.

The vertical centerline of each machine was used as the primary reference axis for removal motions. The rotational motions of the blanket modules were taken about this axis. The translational motions of the blanket modules were made either vertically or radially from the axis of motion.

The first section of the blanket assembly to be removed is, in all cases, the upper central outboard blanket module. This is accomplished through a single vertical upward motion. The next section is either the right or the left upper plug, followed by the remaining plug. The upper plugs are removed through a single rotation to the center of the port followed by a vertical upward translation. The upper plugs are followed by the inboard blanket/shield modules. The removal of a HARD inboard blanket module required 13 motions while the CDA design inboard blanket module required 10 motions. Many of the motions for inboard blanket removal are common to both the CDA design and the HARD.

Both the CDA and HARD blanket module removal configurations were found to be physically possible. The minimum clearances for both designs were encountered within the first three steps in each case and varied from approximately $20 \mathrm{~mm}$ to $40 \mathrm{~mm}$. However, the decisive factor in determining the preference for the CDA baseline design was the difficultly of maneuvering the HARD inboard blanket modules in the area of the lower central outboard blanket modules. The proximity of these modules makes this a difficult task which will be undesirable under remote maintenance conditions.

Removing the lower central outboard blanket module would facilitate the removal of the inboard blanket modules for both machine configurations. This removal would consist of an upward translation only, but the distance of the lift, coupled with a $2 \mathrm{~cm}$ clearance on all sides, negates the small advantage that it would provide.

\section{Summary}

The HARD requires an increase in the main crane capacity to more than 1000 tons. Remote maintenance tasks in the inboard blanket/shield module area in the upper port facilitated with the HARD. Removal of divertor modules and blanket/shield modules was found to be physically possible for both the CDA design and the HARD. However, the HARD required more removal steps with an increased degree of difficulty.

\section{$\underline{\text { References }}$}

[1] ITER Assembly and Maintenance, ITER Documentation Series No. 34, ITER-IL-MA-1-0-105, ITER Concept ual Design Activity (November 1990). 

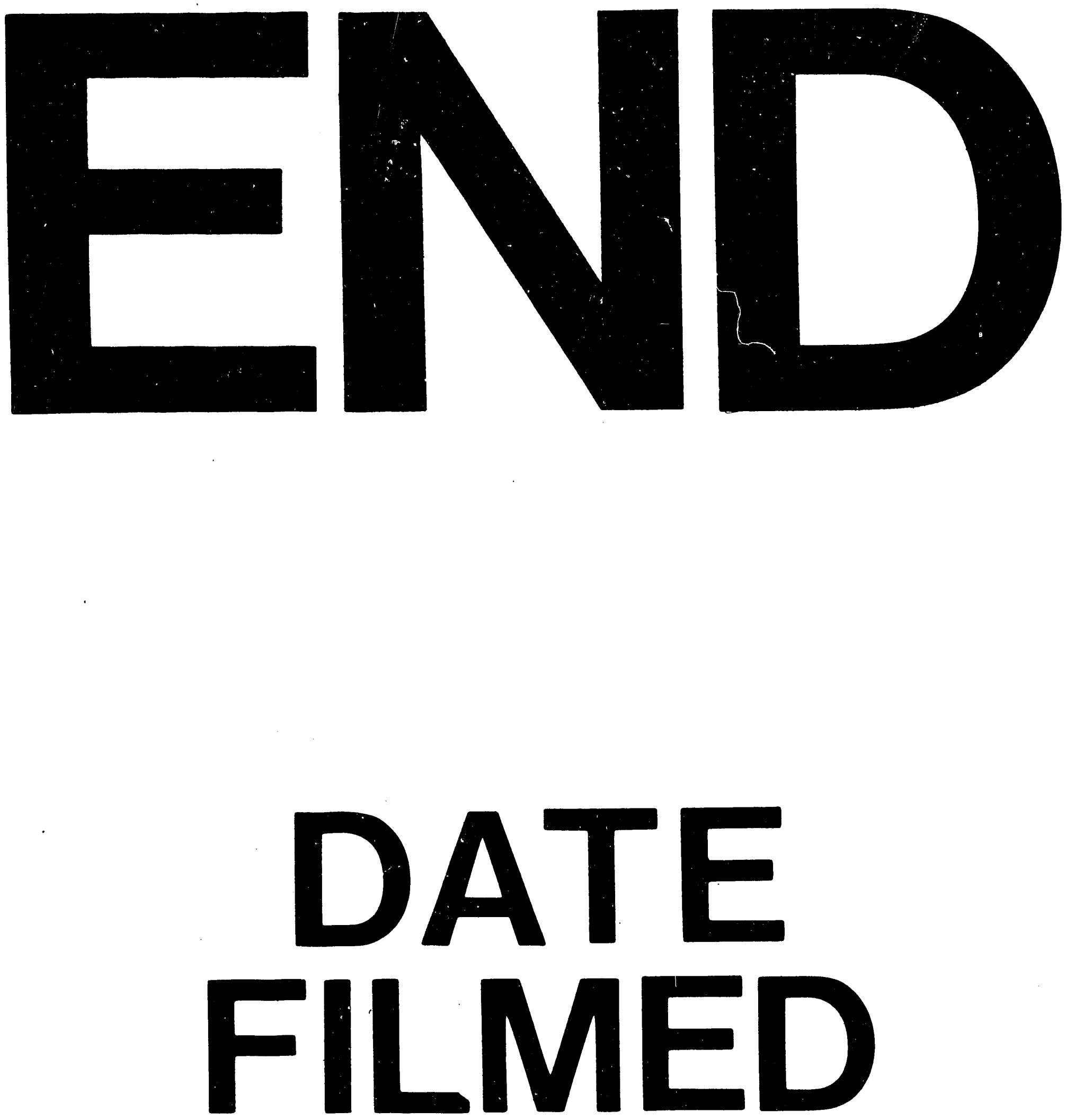

I

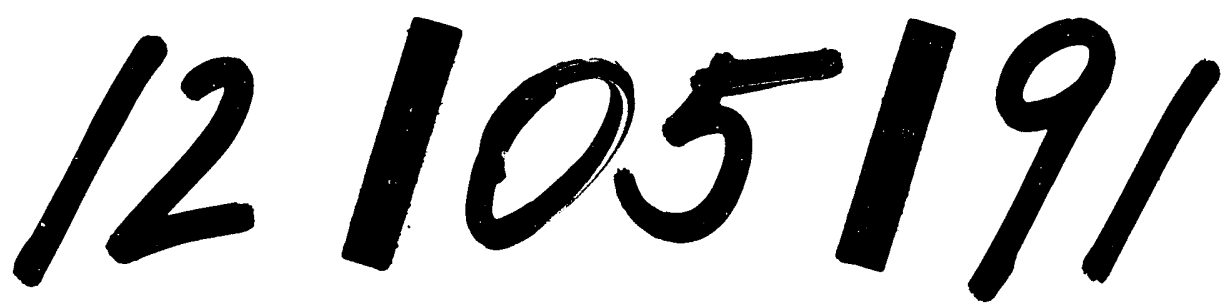


